\title{
Effect of exopolysaccharide from Ganoderma applanatum on the electrical properties of mouse fibroblast cells line L929 culture using an electric cell-substrate impedance sensing (ECIS) - Preliminary study
}

\author{
Monika Prendecka', Radosław Mlak', Magdalena Jaszek², Monika Osińska-Jaroszuk², \\ Monika Jakubiak-Hulicz ${ }^{1}$, Christian Leibold ${ }^{3}$, Armin Bieser ${ }^{3}$, Waldemar Wójcik ${ }^{4}$, \\ Teresa Małecka-Massalska' \\ ${ }^{1}$ Physiology Department, Medical University of Lublin, Poland \\ ${ }^{2}$ Department Biochemistry, Maria Curie-Skłodowska University, Lublin, Poland \\ 3 ibidi GmbH Am Klopferspitz 19 D-82152 Martinsried (München) Germany \\ ${ }^{4}$ Institute of Electronics and Information Technology Technical University of Lublin, Poland
}

Prendecka M, Mlak R, Jaszek M, Osińska-Jaroszuk M, Jakubiak-Hulicz M, Leibold Ch, Bieser A, Wójcik W, Małecka-Massalska T. Effect of exopolysaccharide from Ganoderma applanatum on the electrical properties of mouse fibroblast cells line L929 culture using an electric cell-substrate impedance sensing (ECIS) - Preliminary study. Ann Agric Environ Med. 2016; 23(2): 280-284. doi: 10.5604/12321966.1203891

\begin{abstract}
Introduction and objective. In recent years there has been intensified research on medicinal preparations of fungal origin. Some fungal polysaccharides may directly affect the inhibition of cancer cells proliferation which, stopping the cell cycle, leads to apoptosis. One of these substances (component of extract of Ganoderma spp) is extensively tested for its anti-cancer properties on the tumor cell lines. Electric cell-substrate impedance sensing (ECIS) is an in vitro impedance measuring system using alternating current (AC) to determinate the behaviour of the cells in physiological conditions.

Objective. The aim of the study was to examine the electric properties (resistance, capacitance and impedance) of mouse fibroblasts cell line L929 after treatment by different concentration of crude exopolysaccharides from Ganoderma applanatum (GpEPS) in real time by ECIS technique.

Materials and methods. For the study, the L929 cell line culture was treated by different concentrations of GpEPS: C1=228.5 $\mu \mathrm{g} / \mathrm{mL} ; C 2=22.85 \mu \mathrm{g} / \mathrm{mL} ; C 3=2.285 \mu \mathrm{g} / \mathrm{mL} ; C 4=0.2285 \mu \mathrm{g} / \mathrm{mL}$; and C5=0.02285 $\mu \mathrm{g} / \mathrm{mL}$. Default optimal frequencies were used: Resistance (R) $4000 \mathrm{~Hz}$, Impedance (Z) $16000 \mathrm{~Hz}$, Capacitance (C) $64000 \mathrm{~Hz}$.

Results. The study demonstrated that GpEPS had no significant effect on the resistance, capacitance and impedance cells cultures, which implies that there is no significant effect on the physiological processes of L929 fibroblasts. This indicates the possibility of using GpEPS preparation in anti-cancer therapy.

Conclusions. In the future, following further studies (comprising in preventive and therapeutic actions), GpEPS can be safely used in anti-cancer therapy which does not cause side-effects or damage to healthy cells.
\end{abstract}

\section{Key words}

ECIS, impedance, resistance, capacitance

\section{INTRODUCTION}

In recent scientific literature there often occurs an assertion that some fungal polysaccharides may directly influence the inhibition of cancer cells proliferation by altering intracellular signals which, in turn, stops the cell cycle and leads to apoptosis. Among the many fungal species, the genus Ganoderma seems to be especially interesting, mainly due to its wide therapeutic effect [1]. One of the most frequently studied biological properties of fungal polysaccharides is their anti-tumour activity, the effect of which depends on their immunomodulatory activities affected by many physical and chemical properties. These include the chemical composition of the molecule, degree of branching, type of

Address for correspondence: Monika Prendecka, Physiology Department, Medical University of Lublin, Radziwiłłowska 11, 20-080 Lublin, Poland

E-mail: m.prendecka@gmail.com

Received: 21 July 2015; accepted: 08 February 2016 glycosidic bonds and conformation, or molecular weight [2]. Since biologically-active extracts of Ganoderma spp. are extensively tested for their anti-cancer properties on the tumour cell lines, it appears appropriate to verify their effects on healthy cells. The presented study demonstrates a useful and effective method of assessing the impact of examined substances on the cells and their properties.

Electric cell-substrate impedance sensing (ECIS) is an in vitro impedance advanced measuring system using alternating current $(\mathrm{AC})$ to determinate the behaviour of cells in physiological conditions. As is well known, cell function modulates cell morphology, and ECIS is capable of detecting and quantifying morphology changes in the sub-nanometer to micrometer range. In ECIS, a small alternating current (I) is applied across the electrode pattern at the bottom of the ECIS arrays. This results in a potential (V) across the electrodes which is measured by the ECIS device. The pioneers of this technique were Giaever and Keese who developed the electric 
cell-substrate impedance sensing (ECIS) as a continuous monitoring system for studying cell behaviours using a non-invasive, real-time, and label-free method [3]. In this system, electrodes are used to apply low alternating current, and electrodes measuring the voltage change mounted at the bottom of a standard matrix. Impedance is measured according to Ohm's law, $\mathrm{Z}=\mathrm{V} / \mathrm{l}$. When the cells attach to the matrix and electrodes they act as insulators, increasing impedance. The flow of the current is hampered depending on the number of cells covering the electrode, and the shape and type of the cells attached to the electrode surface. The structure design of ECIS measuring system includes: two electrodes (one is a small working electrode and the other a large counter electrode on the bottom of the culture plate) connected to the edge of a culture chip which is connected to the lock-in amplifier. The whole setup is placed inside an incubator in stable conditions: $37^{\circ} \mathrm{C}$ and under a $5 \% \mathrm{CO}_{2}$ atmosphere. After seeding, cells drift downward and attach to the stratum of the electrode, which then passes the impeded current directly into the bulk electrolyte as the result of anchored plasma membrane intrusion above the electrode surface [4]. The direct parameters derived from impedance measurements are resistance and capacitance of the cells [5].

The quality and function of the cell barrier is represented by the resistance; therefore, the resistance towards paraand trans-cellular current flow should be considered. Capacitance provides an overall measure of electrode coverage. Therefore, the different behaviour of the cells after the seeding, adherence, proliferation and their reaction to substances added to the substrate as a result, produce change in impedance [6].

\section{OBJECTIVES}

The study aimed to examine the relationship between electrical changes within cells, or on their surfaces, and the processes conditioning the survival of fibroblast cells line L929 subjected to various concentrations of GpEPS.

\section{MATERIAL AND METHODS}

Microorganism and culture conditions. The G. applanatum strain (Fungal Collection (FCL) of the Biochemistry Department, Maria Curie-Sklodowska University, Lublin, Poland) cultures were maintained on potato-dextrose-agar (PDA) plates, which were inoculated and incubated at $25^{\circ} \mathrm{C}$ for 7 days and stored at $4^{\circ} \mathrm{C}$. The experimental inocula were prepared in $100 \mathrm{~mL}$ Elenmeyer flasks containing $25 \mathrm{~mL}$ of the PDA medium at $25^{\circ} \mathrm{C}$ for 7 days. After the inoculation with $4 \%(\mathrm{v} / \mathrm{v})$ of the homogenate, rotary shaking cultures were incubated in $250 \mathrm{~mL}$ Erlenmeyer flasks containing $100 \mathrm{~mL}$ medium. The media consisted of the following components: $30 \mathrm{~g} / \mathrm{L}$ glucose, $1 \mathrm{~g} / \mathrm{L}\left(\mathrm{NH}_{4}\right)_{2} \mathrm{SO}_{4}, 0.5 \mathrm{~g} / \mathrm{L} \mathrm{KH}_{2} \mathrm{PO}_{4}, 0.5 \mathrm{~g} / \mathrm{L}$ $\mathrm{MgSO}_{4} \times 7 \mathrm{H}_{2} \mathrm{O}, 0.01 \mathrm{~g} / \mathrm{L} \mathrm{FeSO}_{4} \times 7 \mathrm{H}_{2} \mathrm{O}$, and $1 \mathrm{~g} / \mathrm{L}$ yeast extract. The experiments were performed at $25^{\circ} \mathrm{C}$ in a rotary shaker $(120 \mathrm{rpm})$ for 12 days. After this time, the culture liquid was separated from the mycelium by centrifugation for $15 \mathrm{~min}$ in $4^{\circ} \mathrm{C}$ at $10,000 \mathrm{rpm}$.

Extraction of exopolysaccharides. Crude exopolysaccharides in the culture liquid were precipitated with cold $96 \%$ ethanol in the ratio $1: 4(\mathrm{v} / \mathrm{v})$ and kept overnight at $4^{\circ} \mathrm{C}$. The resulting preparation was centrifuged (10,000 rpm, $10 \mathrm{~min}$.), washed 3 times with ethanol, dissolved in distilled water, and lyophilized.

The amount of proteins, total polysaccharides, reducing sugar, and total phenolic compounds content of GpEPS, was estimated as in an earlier report [7] (Tab. 1).

Determination of total carbohydrate and reducing sugar. The total carbohydrate content of the exopolysaccharides was determined according to Dubois et al. [8] using the phenol-sulfuric acid assay with D-glucose as a standard. The concentration of reducing sugars was measured by the Somogyi-Nelson method, based on the procedure described by Hope and Burns [9], with some modifications. The amount of total reducing sugars was calculated with D-glucose as a standard. The final total value of polysaccharides was obtained by subtraction of reducing sugars from the total carbohydrates.

Determination of proteins and phenolic compounds. The protein concentration was estimated by the Coomassie brilliant blue (G-250) dye-binding method [10] using Bio-Rad dye stock solution with bovine serum albumin (Sigma) as a standard. The total phenolic compounds content of GpEPS was determined with diazosulfanilamide by the DASA test [11]. The changes in absorbance were measured at $500 \mathrm{~nm}$ and compared with the standard curve of vanillic acid.

Table 1. Amount of proteins, total polysaccharides, reducing sugar, and total phenolic compounds content of tested GpEPS preparation [5]

\begin{tabular}{ccccccc}
\hline $\begin{array}{c}\text { Prep- } \\
\text { aration }\end{array}$ & $\begin{array}{c}\text { Extrac- } \\
\text { tion } \\
\text { yield }\end{array}$ & $\begin{array}{c}\text { Protein } \\
\text { contents } \\
(\mathrm{mg} / \mathrm{g})\end{array}$ & $\begin{array}{c}\text { Total } \\
\text { carbo- } \\
\text { hydrate } \\
(\mathrm{mg} / \mathrm{g})\end{array}$ & $\begin{array}{c}\text { Total } \\
\text { poly- } \\
\text { saccharide } \\
(\mathrm{mg} / \mathrm{g})\end{array}$ & $\begin{array}{c}\text { Reducing } \\
\text { sugar } \\
(\mathrm{mg} / \mathrm{g})\end{array}$ & $\begin{array}{c}\text { Total } \\
\text { phenolic } \\
\text { compounds } \\
(\mu \mathrm{M} / \mathrm{g})\end{array}$ \\
\hline GpEPS & $8.13 \pm 0.4$ & $22.6 \pm 0.07$ & $303 \pm 1.29$ & $241.8 \pm 2$ & $61.2 \pm 1.2$ & $12 \pm 0.4$ \\
\hline
\end{tabular}

Cell lines and culture conditions. In the initial phase, cells of mouse fibroblast cell line - NCTC clone 929 [L cell, L-929, derivative of Strain L] (ATCC ${ }^{\circledast}$ CCL- $^{\mathrm{TM}}{ }^{\mathrm{TN}}$ ) was derived from ATCC and cultured according to the instruction manual. The cells of L929 were cultured in complete Eagle MEM medium (Sigma Aldrich) supplemented with 10\% foetal bovine serum FBS Good HI, in an Galaxy 170R incubator, under controlled growth conditions, constant humidity and air saturation of $5 \% \mathrm{CO}_{2}$. After multiplication and stabilization of the cells (approx. 7 - 14 days), when the culture reaches at least 75\% confluence, the next stage of testing was culturing the cells with GpEPS in different concentrations.

The electric cell-substrate impedance sensing. The study was conducted by means of monitoring selected electrical parameters: resistance, capacitance and impedance in cell cultures, in real time.

The ECIS system used (ibidi GmbH) contained 2 separate units: station controller $\mathrm{Z} \theta$, located outside of the incubator, and the station (96 wells) placed within the incubator space. The station was connected with a $6 \mathrm{ft}$ long flat cable which was plugged into a socket on the back panel of the station controller that was then covered with a shield / strain relief cover. The station controller contained most of the electronics, including the oscillator supplying the AC signal 
and sophisticated impedance measuring circuits. The array station provided additional signal processing circuits and switching mechanisms to change the measurement from well to well. The instrument was capable of simultaneously measuring both the resistance and capacitance of the ECIS electrodes over a broad range of AC frequencies. In addition, the electronics only accept signals having the same frequency as that of the source oscillator and is said to 'lock' to the signal, eliminating most extraneous electrical noise.

The standard 96 well ECIS disposable arrays consist of gold electrodes delineated with an insulating film and mounted on opaque fiberglass supports. The 96 well top assembly is made of polystyrene and each well has a surface area for cell attachment and growth of $\sim 0.3 \mathrm{~cm}^{2}$ and holds a maximum volume of $\sim 400$ microliters. A PCI connector on the top edge of the array connects electrodes to the ECIS electronics via contact with a special socket on the electrode array station. The 96W1E ECIS array - 96 wells, with one active electrode per well, was used. Each electrode is 250 micrometers in diameter.

Prior to inoculation, the array was incubated with the Eagle MEM medium in the Galaxy 170R incubator overnight. Following stabilization, the array was removed from the array station and inoculated with cells. Inoculation of arrays was carried out by 300 microliters per well of cell (L929) suspension at $\sim 1.2 \times 10^{5}$ cell $/ \mathrm{ml}$. GpEPS was added to inoculated wells to final concentrations of: $228.5 \mu \mathrm{g} / \mathrm{mL}$ (C1); $22.85 \mu \mathrm{g} / \mathrm{mL}$ (C2); $2.285 \mu \mathrm{g} / \mathrm{mL}$ (C3); $0.2285 \mu \mathrm{g} / \mathrm{mL}$ (C4); $0.02285 \mu \mathrm{g} / \mathrm{mL}$ (C5). Following cell manipulation, the array holder was placed in the incubator and real time measurements were initialized. The maximum response for $\mathrm{Z}, \mathrm{R}$ and $\mathrm{C}$ occurs at different frequencies. In this study the default optimal frequencies were used: Resistance (R) $4000 \mathrm{~Hz}$, Impedance (Z) $16000 \mathrm{~Hz}$, Capacitance (C) $64000 \mathrm{~Hz}$.

\section{RESULTS}

The effect of varying GpEPS concentrations on L929 monolayer cell culture and electric changes were continuously monitored for up to 35 hours. Using the ECIS system, important changes in resistance, impedance, and capacitance in L929 cells following administration of 5 different concentrations of GpEPS were recorded. Based on the obtained results, it can be concluded that different doses of GpEPS affect electrical parameters of cell culture in different mode (Fig. 1-3). Every cell type has its characteristic adhesion and growth curve that can be manipulated by e.g. varying seeding density or other stimuli - concentration of substances in the medium. One of the major difficulties to study those processes is to differentiate between adhesion, spreading and proliferation.

As can be noted (Fig. 1), initially at starting in the first 10 hours, the resistance increases in all cell cultures: F (control culture of fibroblasts L929 cells) and L929 cells culture treated by $228.5 \mu \mathrm{g} / \mathrm{mL}(\mathrm{C} 1) ; 22.85 \mu \mathrm{g} / \mathrm{mL}$ (C2); $2.285 \mu \mathrm{g} / \mathrm{mL}$ (C3); $0.2285 \mu \mathrm{g} / \mathrm{mL}$ (C4); $0.02285 \mu \mathrm{g} / \mathrm{mL}$ (C5) of GpEPS, due to attachment and spreading, followed by confluence of the cells. After the next 10 hours of incubation, it can be seen that nearly all tested concentrations of GpEPS caused an increase in resistance up to nearly $4,000 \mathrm{ohms}$, in comparison to control lines $(\mathrm{F}=3,600 \mathrm{ohms})$. In this period of time (between the $10^{\text {th }}-20^{\text {th }}$ hour of incubation), only the dose of $0.02285 \mu \mathrm{g} / \mathrm{mL}$ (C5) of GpEPS did not increase the resistance when compared to the control cultures $(\mathrm{F})$. In the case of $\mathrm{C} 5$, that condition lasted for next 5 hours, after which the resistance increased up to $4,300 \mathrm{ohms}$ in comparison to F cultures $(4,100 \mathrm{ohms})$, but still stayed at similar level. The highest resistance were observed in the case of $\mathrm{C} 1, \mathrm{C} 2$ and C3 cultures, and exceeded 4,500 ohms after 20 hours. The C5 concentration had the greatest impact on the cells and resulted in the biggest increase in resistance and the longest duration (4,500 ohms up to 29 hours). In contrast, the resistance of F, C1, C2, C3 and C4 cultures dropped drastically after 25 hours.

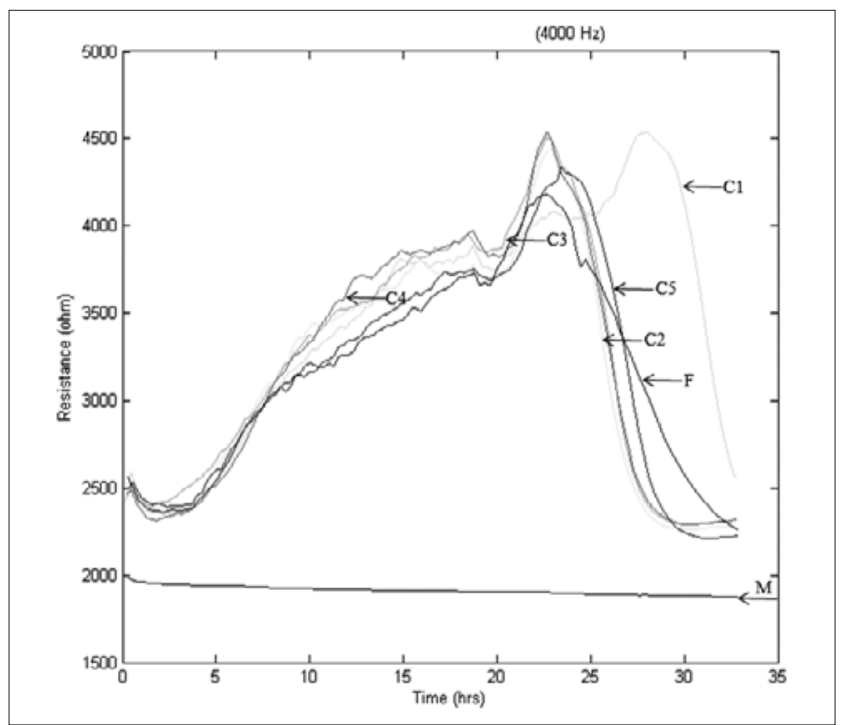

Figure 1. Changes in resistance of cell lines.

$\mathrm{F}$ - control cell line of L929; C1 - cell line of L929 treated with GpEPS, concentration - $228.5 \mu \mathrm{g} / \mathrm{mL}$; C2 - cell line of L929 treated with GpEPS, concentration - 22.85 $\mu \mathrm{g} / \mathrm{mL}$; C3 - cell line of L929 treated with GpEPS, concentration - $2.285 \mu \mathrm{g} / \mathrm{mL}$; C4 - cell line of L929 treated with GpEPS, concentration - $0.2285 \mu \mathrm{g} / \mathrm{mL}$; C5 - cell line of L929 treated with GpEPS, concentration - $0.02285 \mu \mathrm{g} / \mathrm{mL} ; \mathrm{M}$ - medium

The ECIS data (Fig. 2) shows that the capacitance of the control culture $(\mathrm{F})$ and cells cultured with the addition of

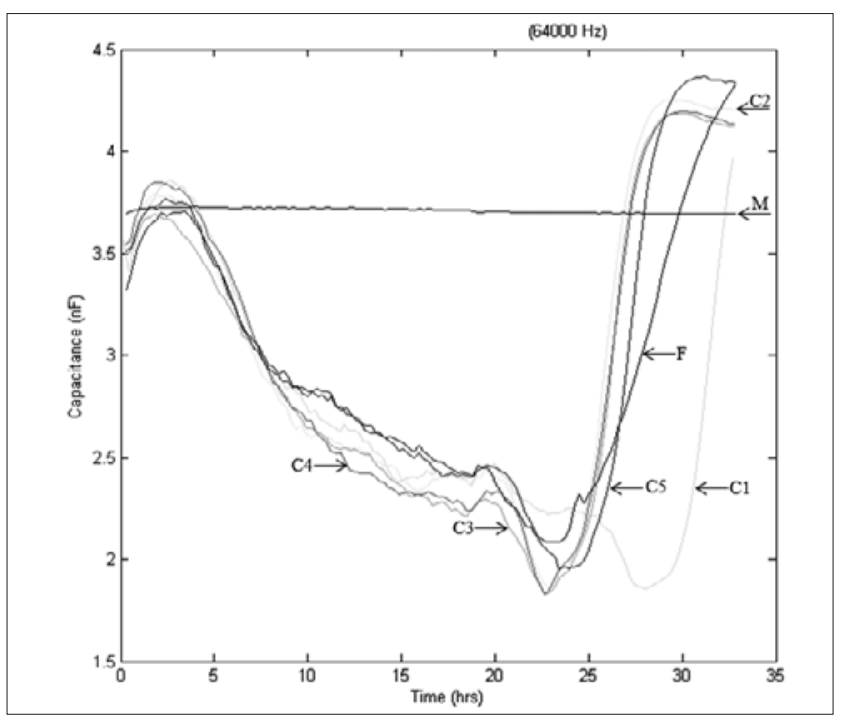

Figure 2. Changes in capacitance of the L929 cell line cultures.

F - control cell line of L929; C1 - cell culture treated with GpEPS, concentration $228.5 \mu \mathrm{g} / \mathrm{mL}$; C2 - cell culture treated with GpEPS, concentration - $22.85 \mu \mathrm{g} / \mathrm{mL}$; $\mathrm{C} 3$ - cell culture treated with GpEPS, concentration - $2.285 \mu \mathrm{g} / \mathrm{mL} ; \mathrm{C} 4$ - cell culture treated with GpEPS, concentration $-0.2285 \mu \mathrm{g} / \mathrm{mL}$; $\mathrm{C} 5$ - cell culture treated with GpEPS, concentration - $0.02285 \mu \mathrm{g} / \mathrm{mL} ; \mathrm{M}$ - medium 
different concentrations of the GpEPS demonstrated a similar pattern, and similar values in all cases. As in the case of resistance, the largest effects on capacitance of cells was caused by the concentration of GpEPS in C5 (decrease to about $1.8 \mathrm{nF}$ after 28 hours of incubation).

In the current study it was found that when L929 cells were treated with GpEPS the impedance only slightly changed their function, and in cell morphology, slightly altered the impedance (Fig. 3). The impedance highest values (about 4,500 ohms) were recorded for L929 cultures treated with the examined substance; time range from $15^{\text {th }}-30^{\text {th }}$ hour. Simultaneously, the strongest proliferative effect on fibroblasts cells was exerted by GpEPS in all concentration (C1 - C5), compared to control cultures (4,000 ohms), which only confirms its medicinal potential.

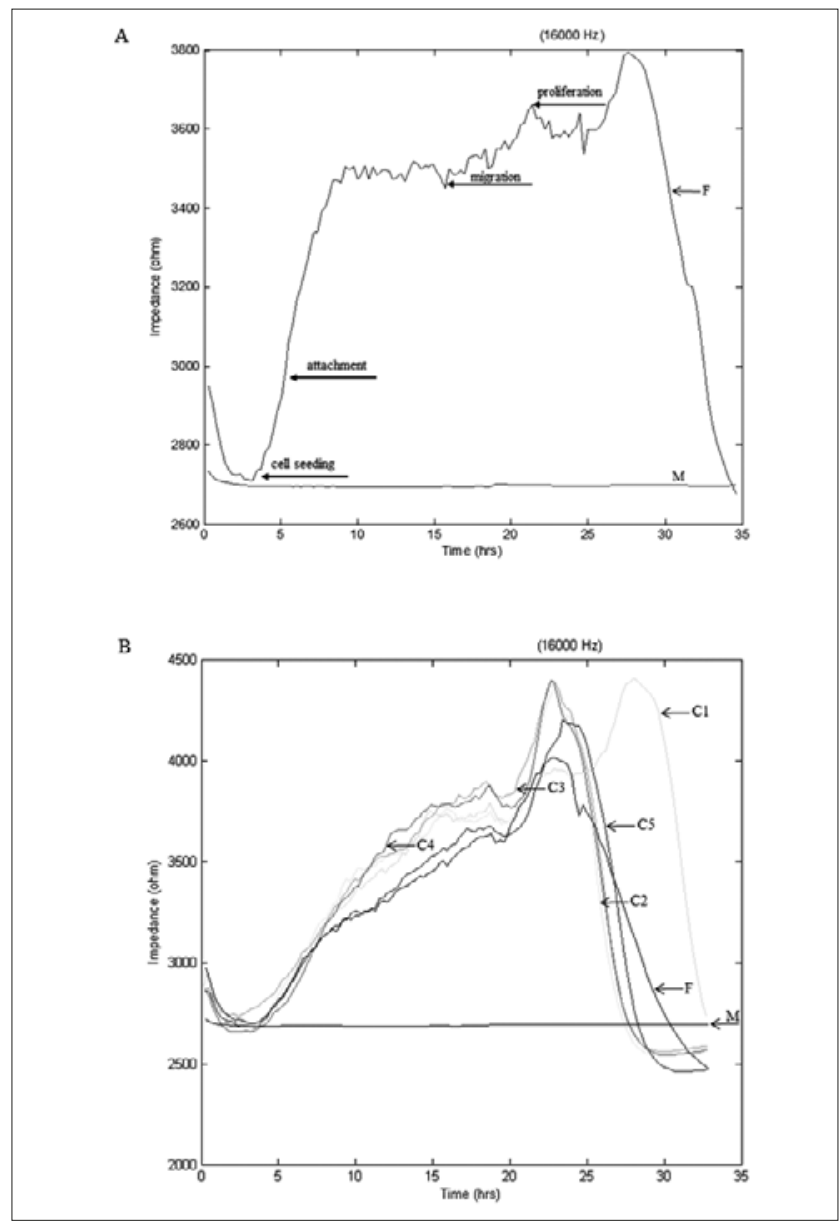

Figure 3. Changes in impedance of the L929 cell line cultures

A - Impedance pattern of normal L929 cell line culture, showing corresponding cellular morphological changes; B - Changes in the impedance of cell line L929 cultures; F - control; C1 - treated with GpEPS, concentration - $228.5 \mu \mathrm{g} / \mathrm{mL}$; C2 - treated with GpEPS, concentration - $22.85 \mu \mathrm{g} / \mathrm{mL} ; \mathrm{C} 3$ - treated with GpEPS, concentration - $2.285 \mu \mathrm{g} / \mathrm{mL}$; C4 - treated with GpEPS, concentration - $0.2285 \mu \mathrm{g} / \mathrm{mL}$; C5 - treated with GpEPS, concentration of $0.02285 \mu \mathrm{g} / \mathrm{mL}$; M - medium

\section{DISCUSSION}

Fungal species belonging to the genus Ganoderma are known for their ability to produce a number of substances with promising biomedical properties [7]. The fruiting bodies of G. applanatum are very often used in traditional Chinese medicinal therapies. They are known as very efficient anti- cancer, immunostimulatory, and anti-viral factors [12, 13]. In the studies by Osińska-Jaroszuk et al. the crude exopolysaccharides (GpEPS) extracted from G. applanatum were subjected to in vitro cytotoxicity assays against carcinoma cell lines (SiHa and CaSki) and a human skin fibroblast (HSF) line. The results showed that the isolated polysaccharides exhibited cytotoxic activity against the SiHa carcinoma cell line and stimulated production of Il- 6 and TNF- $\alpha$ by the macrophage line THP-1 [7]. Since the aim of the presented study was to demonstrate that GpEPS can be safely used in anti-cancer therapy, and does not cause side- effects or damage to healthy cells, it was therefore important to determine the impact of GpEPS on healthy fibroblasts cell line L929 culture. Traditionally, microscopy (inverted, confocal, fluorescence), spectrophotometry, colourimetry, ELISA, flow cytometry techniques etc., are considered standard in studies conducted on cell cultures. While these methods may provide insight into the physiological function of each single cell or into pathological changes that could have occurred, they usually require fluorescence, chemiluminescence or radioactive ways of marking, which lead to cell destruction. The process causes loss of important biological information about living cells. An innovative method used for the monitoring of live cells is the real time analysis of selected electrical parameters (i.e. cell membrane capacity, resistance or impedance). By registering the above-mentioned parameters of cells cultured on the electrode surface, the ECIS technique may directly provide detailed information about the cellular activity and eliminate the methods of multiple marking, thus facilitating non-invasive examination of cellular properties in real time.

Every cell type has its characteristic adhesion and growth curve that can be manipulated by e.g. varying the seeding density or other stimuli. Wegener et al. [14] described in detail the use of a combination of resistance and capacitance to distinguish between those parameters. The results of the current work coincide with Wegener's observations on resistance and capacitance, and complement each other (Fig. 1, 2). After 25 hours, resistance began to fall in all cell lines, which should be interpreted as a progressive cell death. The decrease of resistance was not observed prior to this time in all cells treated with C1-C5 doses of GpEPS and in control cells $(F)$, which may indicate that GpEPS does not exert anti-proliferative nor cytotoxic activity towards L929 cells. The decrease in capacitance (Fig. 2) indicates cell proliferation, while increase in the resistance corresponds to cell proliferation, which is why both values complement each other. According to Szulcek et al. [5], the resistance represents the quality and function of the cell barrier, and therefore takes into consideration the resistance towards para- and trans-cellular current flow. Capacitance provides an overall measure of electrode coverage. The variation in cell behaviour after cell attachment, spreading, proliferation, micromotion, demise, and/or responses to external substances, result in changes in impedance [15]. The electrical impedance is defined as the opposition to an electrical current within a circuit. In systems utilizing direct current, the impedance is simply the resistance, but in systems utilizing alternating currents, the changing electric and magnetic fields create additional and varying opposition to the applied current [16]. ECIS is a system using alternating current.

In the current study, it was found that when L929 cells cultures were treated with GpEPS it did not changed their function substantially, and the slight alterations in impedance 
may correspond to changes in the cell morphology (Fig. 3). In Figure $3 \mathrm{~A}$ a characteristic variation can be observed in cell behaviour after cell attachment, spreading, proliferation and micromotion, similar to those described by Xiaoqiu et al. and Ramasamy et al. $[15,17]$. As demonstrated in the current study, GpEPS had no significant effect on the resistance, capacitance and impedance of L929 cell line; however, the observed electrical changes are noteworthy and indicate the possibility of using the examined preparation in anti-cancer research and therapy.

\section{CONCLUSIONS}

Based on the results of the study, it was found that the GpEPS did not change significantly the electrical parameters (resistance, capacitance and impedance) of normal mouse fibroblast cells. As there is a close connection between electrical changes within cells or on their surfaces, and the processes conditioning cell survival, it can be concluded that although GpEPS exhibited cytotoxic activity against e.g. the $\mathrm{SiHa}$ carcinoma cell line, it can be safely used in anti-cancer research and therapy because it does not cause side-effects or damage to healthy cells. However, further studies comprising preventive and therapeutic actions of the GpEPS fraction are needed.

\section{REFERENCES}

1. Paterson R R M. Ganoderma-a therapeutic fungal biofactory. Phytochemistry. 2006; 67(18): 1985-2001.

2. Methacanon P, Madla S, Kirtikara K, Prasitsil M. Structural elucidation of bioactive fungi-derived polymers. Carbohydr Polym. 2005; 60(2): 199-203.

3. Giaever I, Keese CR. Monitoring fibroblast behavior in tissue culture with an applied electric field. Proc. Natl Acad Sci. (USA) 1984; 81: 3761-3764.
4. Giaever I, Keese CR. A morphological biosensor for mammalian cells. Nature, 1993, 366 (6455):591-592.

5. Szulcek R, Bogaard H J, van Nieuw Amerongen G P. Electric Cellsubstrate Impedance Sensing for the Quantification of Endothelial Proliferation, Barrier Function, and Motility. J Vis Exp. 2014; 85: e51300, doi:10.3791/51300.

6. Xiao C, Lachance B, Sunahara G, and Luong J H T. Assessment of Cytotoxicity Using Electric Cell-Substrate Impedance Sensing: Concentration and Time Response Function Approach. Anal Chem. 2002; 74: 5748 - 5753 .

7. Osińska-Jaroszuk M, Jaszek M, Mizerska-Dudka M, Błachowicz A, Rejczak TP, Janusz G, et al. Exopolysaccharide from Ganoderma applanatum as a Promising Bioactive Compound with Cytostatic and Antibacterial Properties. Hindawi Publishing Corporation BioMed Res Int. 2014; Article ID 743812, 10 pages http://dx.doi. org/10.1155/2014/743812.

8. Dubois M, Gilles K A, Hamilton J K, Rebers P A, and Smith F. Colorimetric method for determination of sugars and related substances. Anal Chem. 1956; 28(3): 350-356.

9. Hope C F A, Burns R G. Activity, origins and location of cellulases in a silt loam soil. Biol Fertil Soils. 1987; 5(2): 164-170.

10. Bradford M M. A rapid and sensitive method for the quantitation of microgram quantities of protein utilizing the principle of protein dye binding. Analytical Biochemistry. 1976; 72(1-2): 248-254.

11. Malarczyk E. Transformation of phenolic acids by Nocardia. Acta Microbiol Polonica, 1998; 38(1): 45-53.

12. Usui T, Iwasaki Y, Mizuno T, Tanaka M, Shinkai K, Arakawa M. Isolation and characterization of antitumor active $\beta$-d-glucans from the fruit bodies of Ganoderma applanatum. Carbohydrate Res. 1983; 115(1): 273-280.

13. Lee WY, Park Y, Ahn JK, Ka K H, Park SY. Factors influencing the production of endopolysaccharide and exopolysaccharide from Ganoderma applanatum. Enzyme Microb Technol. 2007; 40(2): 249254.

14. Wegener J, Keese CR, Giaever I. Electric cell-substrate impedance sensing (ECIS) as a noninvasive means to monitor the kinetics of cell spreading to artificial surfaces. Exp Cell Res. 2000; 259(1): 158-166.

15. Xiaoqiu H, Nguyen D, Greve DW, Domach MM. Simulation of microelectrode impedance changes due to cell growth. IEEE Sens J. 2004; 4(5): 576-583.

16. Coffman FD and Cohen S. Impedance measurements in the biomedical Sciences. Anal Cellular Pathol. 2012; 35: 363-374 doi 10.3233/ACP2012-0070.

17. Ramasamy S, Bennet D, Kim S. Drug and bioactive molecule screening based on a bioelectrical impedance cell culture platform. Int J Nanomed. 2014; 9: 5789-5809. 